\title{
Multiplex Ligation-Dependent Probe Amplification Analysis of the NROB1 (DAX1) Locus Enables Explanation of Phenotypic Differences in Patients with X-Linked Congenital Adrenal Hypoplasia
}

\author{
Michela Barbaro ${ }^{a, b}$ Susanne Bens ${ }^{c}$ Andrea Haake ${ }^{c}$ Michael Peter ${ }^{e}$ Jürgen Brämswig ${ }^{f}$ \\ Paul-Martin Holterhus $^{d}$ Juan Pedro Lopez-Sigueroi Udo Menkeng Monika Mix ${ }^{\mathrm{h}}$ \\ Wolfgang G. Sippell ${ }^{d}$ Anna Wedell ${ }^{a, b}$ Felix G. Riepe ${ }^{d}$ \\ ${ }^{a}$ Department of Molecular Medicine and Surgery, and ${ }^{b}$ Centre for Inherited Metabolic Diseases, Karolinska \\ Institutet, Stockholm, Sweden; 'Institute of Human Genetics, and d Department of Pediatrics, Christian Albrechts \\ University Kiel and University Hospital Schleswig-Holstein, Campus Kiel, Kiel, e Screening Laboratory, Hannover, \\ fDepartment of Pediatrics, Westfälische Wilhems University, Münster, ${ }^{9}$ Department of Pediatrics, Ruhr University, \\ Bochum, and h'Department of Pediatrics, University of Rostock, Rostock, Germany; 'Department of Pediatrics, \\ Hospital Materno-Infantil, Malaga, Spain
}

\section{Key Words}

Adrenal hypoplasia congenita $\cdot$ NROB1 $\cdot$ Multiplex ligation-dependent probe amplification - Contiguous gene deletion

\footnotetext{
Abstract

Background/Aim: X-linked adrenal hypoplasia congenita $(\mathrm{AHC})$ is a rare disorder characterized by primary adrenal insufficiency and hypogonadic hypogonadism. It is caused by deletions or point mutations of the NROB1 gene, on Xp21. $\mathrm{AHC}$ can be associated with glycerol kinase deficiency, Duchenne muscular dystrophy and mental retardation (MR), as part of a contiguous gene deletion syndrome. A synthetic probe set for multiplex ligation-dependent probe amplification analysis was developed to confirm and characterize $N R O B 1$ deletions in patients with $\mathrm{AHC}$ and to correlate their genotypes with their divergent phenotypes. Results: In 2 patients, isolated AHC was confirmed, while a patient at risk for metabolic crisis was revealed as the deletion extends to
}

the GK gene. A deletion extending to ILIRAPL1 was confirmed in both patients showing MR. Thus, a good genotype-phenotype correlation was confirmed. Conclusions: Multiplex ligation-dependent probe amplification analysis is a valuable tool to detect NROB1 and contiguous gene deletions in patients with AHC. It is especially helpful for IL1RAPL1 deletion detection as no clinical markers for MR are available. Furthermore, multiplex ligation-dependent probe amplification has the advantage to identify female carriers that, depending on the deletion extension, have a high risk of giving birth to children with MR, AHC, glycerol kinase deficiency and Duchenne muscular dystrophy.

Copyright $\odot 2012$ S. Karger AG, Basel

\section{Introduction}

$\mathrm{X}$-linked congenital adrenal hypoplasia (AHC) is a developmental disorder of the human adrenal cortex. Although rare, it is the most common form of primary

\section{KARGER \\ Fax +41613061234 \\ E-Mail karger@karger.ch}

www.karger.com (c) 2012 S. Karger AG, Basel

$1663-2818 / 12 / 0772-0100 \$ 38.00 / 0$

Accessible online at:

www.karger.com/hrp
Michela Barbaro

Karolinska Institutet, Department of Molecular Medicine and Surgery

CMM L8:02, Karolinska University Hospital

SE-17176 Stockholm (Sweden)

Tel. +46 85177 3922, E-Mail Michela.barbaro@ki.se 
adrenal hypoplasia reported [1]. It is characterized by primary adrenal insufficiency (AI), hypogonadic hypogonadism $(\mathrm{HH})$ and a defect in spermatogenesis. AI has an apparent bimodal manifestation onset, generally presents with severe salt-losing adrenal crisis within the first 2 months of life or it can manifest in a more insidious manner with adrenal failure during childhood. HH manifests during adolescence as absent or arrested puberty due to hypothalamic and pituitary defects.

$\mathrm{X}$-linked AHC is caused by deletions or point mutations of the NROB1 (DAX1) gene, located on Xp21.2 [2, 3]. NROB1 encodes for an orphan nuclear receptor that is expressed in the developing adrenal gland, the gonads, the hypothalamus and the pituitary gland [4]. Duplications of the NROB1 locus are responsible for XY gonadal dysgenesis $[5,6]$.

Deletions can affect the NROB1 gene alone or extend to the neighboring genes; thus, AHC can be detected as part of a contiguous gene syndrome (CGS) together with glycerol kinase deficiency (GKD), Duchenne muscular dystrophy (DMD) and mental retardation (MR). It has been calculated that isolated and contiguous NROB1 gene deletions account for 22 and $5 \%$ of all NROB1 mutations, respectively [7].

GKD is caused by mutations or deletions of the gene for glycerol kinase (GK), an enzyme involved in the glycerol metabolism. GKD, even in the isolated form, presents with variable phenotypes, and even within the same family, these range from asymptomatic hyperglycerolemia to severe and life-threatening metabolic crisis and/or psychomotor retardation $[8,9]$. DMD, together with Becker muscular dystrophy, is a neuromuscular disease characterized by progressive muscular weakness and degeneration of skeletal muscle and is caused by mutations of the $D M D$ gene; at least $20 \%$ of the patients also show mental impairment [10].

MR associated with AHC cannot be explained with GKD or DMD in every case. Deletions extending to the IL1RAPL1 gene have been shown to be responsible for MR in several cases [11-13]. In fact, partial IL1RAPL1 deletions and nonsense mutations have been described as cause of nonspecific X-linked MR $[11,14,15]$.

The aim of this study was to develop a multiplex ligation-dependent probe amplification (MLPA) synthetic probe set to confirm and characterize NROB1 deletions (fig. 1) in patients with AHC and to correlate their genotypes to the variant phenotypes.

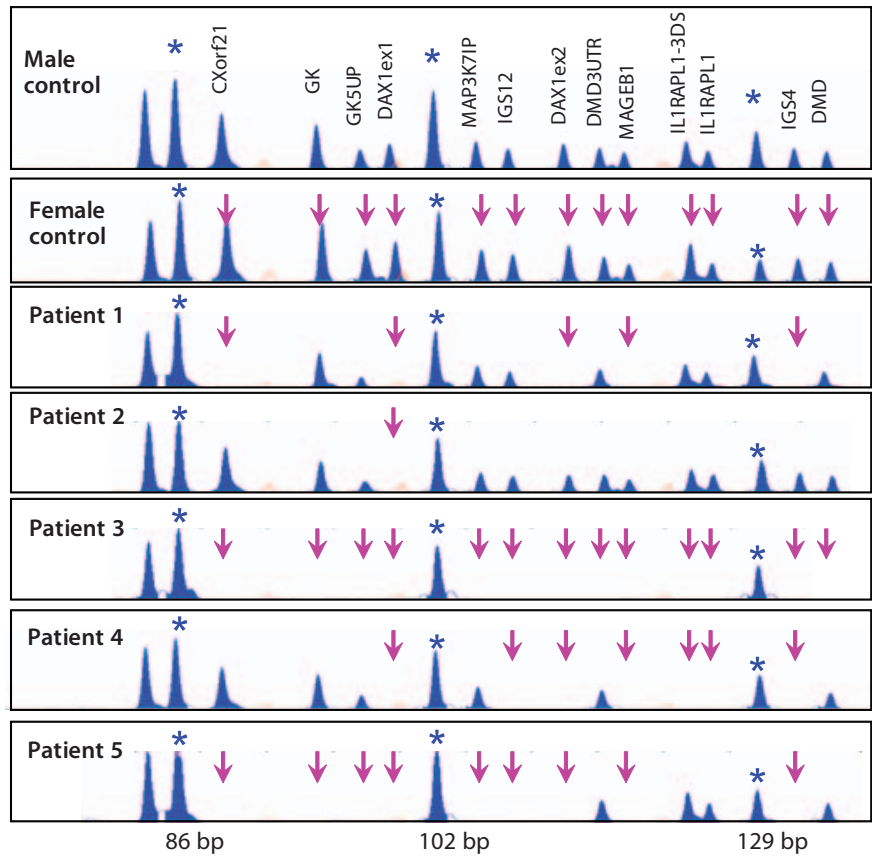

Fig. 1. DAX1-del probe set. MLPA trace results for the DAX1-del probe set. Peaks corresponding to control probes are labeled $\left(^{*}\right)$ and their size in bp is reported along the $\mathrm{x}$-axis at the bottom of the figure. Arrows indicate deleted probes.

\section{Patients and Methods}

\section{Patients}

Five male patients suffering from AHC and their mothers, if available, have been included in the study. All patients manifested with severe salt loss during infancy (mean age at manifestation 3.4 weeks, range 2-5). Aldosterone concentrations in plasma were in the lower normal range, but inadequately low for the degree of hyponatremia and the elevated levels of plasma renin activity. Adrenal glucocorticoid biosynthesis was normal or in the lower range; however, adrenocorticotropin hormone was highly elevated revealing an imminent addisonian crisis. Levels of 17-hydroxyprogesterone were within or below the normal range for respective age. All infants showed normal male external genitalia with slight hyperpigmentation. In 2 out of the 5 patients, testosterone was measured (range 1.2-6.9 nmol/l), revealing levels within the normal range for the minipuberty reflecting testicular androgen biosynthesis [16]. All patients were treated with fludrocortisone by the time of the manifestation of mineralocorticoid deficiency and with hydrocortisone for a diagnosis of glucocorticoid deficiency. An NROB1 deletion was detected previously with polymerase chain reaction (PCR) techniques as cause for the disease [2].

Patient 1 and patient 2 are adults and suffer from AI and permanent $\mathrm{HH}$. Testosterone replacement therapy was initiated during adolescence. Both patients reached a normal final height for the family and population standards. No mental deficits are reported. Patient 3 is a 13.8 -year-old adolescent suffering from AI. Puberty has not started until now and $\mathrm{HH}$ can be anticipated. The 
Table 1. DAX1-del probe set

\begin{tabular}{|c|c|c|c|c|c|c|}
\hline Probe name & $\begin{array}{l}\text { Size } \\
\text { bp }\end{array}$ & $5^{\prime}$ half-probe ${ }^{c}$ & $3^{\prime}$ half-probe ${ }^{c}$ & $\begin{array}{l}\text { SD } \\
\text { height }\end{array}$ & $\begin{array}{l}\mathrm{SD} \\
\text { area }\end{array}$ & $\begin{array}{l}\text { Ratio } \\
\text { median }^{\mathrm{d}}\end{array}$ \\
\hline GABRA $4^{\mathrm{a}}$ & 84 & CAGCCTGTTGTCATAACCATCG & AGCAAACTGTCCAGGATGCG & 0.02 & 0.02 & 1.01 \\
\hline CXorf21 & 90 & CCAGCCACCTGCTCATTATAAGAG & GCACAACTCCAGTGGATGTCATTC & 0.06 & 0.05 & 0.60 \\
\hline GK & 96 & CACTATATGTAGGTTATCTCTTCGGTGACA & TACACTGCAATTTGAGAGGGCTGG & 0.06 & 0.06 & 0.54 \\
\hline GK5UP & 99 & CCTGTCCGAGCGTTCGGCTCTTTTGCGT & TTGCTGATTGGCCAGCCCAGGTGACAGCG & 0.02 & 0.06 & 0.56 \\
\hline DAX1ex1 & 102 & $\begin{array}{l}\text { GCAGCCTCAGCGGGCCTGTTGAAGACG- } \\
\text { CTG }\end{array}$ & CGCTTCGTCAAGTACTTGCCCTGCTTCCAG & 0.02 & 0.03 & 0.55 \\
\hline MAP3K7IPex12 & 108 & $\begin{array}{l}\text { GCTTCTGGTAGTGCTCAAAGTTTCACTTT- } \\
\text { CAA }\end{array}$ & $\begin{array}{l}\text { CCTGGCGCAGACTTTTCTGAATTCAGGTG- } \\
\text { TACCG }\end{array}$ & 0.05 & 0.04 & 0.57 \\
\hline IGS12 & 111 & $\begin{array}{l}\text { GAAGGAATTCTAATATCAGCAGTCTGTG- } \\
\text { AACA }\end{array}$ & $\begin{array}{l}\text { ATGTGAAAATCACTGCCTAAGTCTATTGC- } \\
\text { AGGCACAG }\end{array}$ & 0.02 & 0.02 & 0.55 \\
\hline DAX1ex2 & 114 & $\begin{array}{l}\text { CATTGCTGAACTGTTCTTCAGGCCCATCA- } \\
\text { TCGGCACA }\end{array}$ & $\begin{array}{l}\text { GTCAGCATGGATGATATGATGCTGGAAA- } \\
\text { TGCTCTG }\end{array}$ & 0.03 & 0.03 & 0.55 \\
\hline IL1RAPL1-3DS & 123 & $\begin{array}{l}\text { GCTCCTCTTAACTAGAATCCTTAGTGTAT- } \\
\text { TCTTTCCACCAA }\end{array}$ & $\begin{array}{l}\text { AGTAGTGGAGGTATGTTCACATAATCTGC- } \\
\text { TATTGAACTGC }\end{array}$ & 0.04 & 0.06 & 0.53 \\
\hline IR1LAPL1 & 126 & $\begin{array}{l}\text { CAGCTCTAGCCACTGCCCATCCAGATCTC- } \\
\text { CGTTCTACCTTTCACA }\end{array}$ & $\begin{array}{l}\text { ACACGTACCATTCACAAATGCGTCAGAAA- } \\
\text { CACTACTACG }\end{array}$ & 0.05 & 0.05 & 0.58 \\
\hline$\overline{\mathrm{RB} 1 \mathrm{ex} 23^{\mathrm{b}}}$ & 129 & $\begin{array}{l}\text { GTCACCAATACCTCACATTCCTCGAAGCC- } \\
\text { CTTACAAGTTTCCT }\end{array}$ & $\begin{array}{l}\text { AGTTCACCCTTACGGATTCCTGGAGGGAA- } \\
\text { CATCTATATTTCACC }\end{array}$ & 0.04 & 0.04 & 1.06 \\
\hline IGS4 & 132 & $\begin{array}{l}\text { CCAAGGAAGTCATAACAGCACAATAGCT- } \\
\text { ATAC }\end{array}$ & $\begin{array}{l}\text { AATCTGATAACCTTGTTAGCTCAAATCAA- } \\
\text { AGCTCCTAACAAGTAGGAGAGGTTAGTGC }\end{array}$ & 0.07 & 0.07 & 0.59 \\
\hline$\overline{\mathrm{DMD}}$ & 135 & CATCGCTCTGCCCAAATCATCTGCCATGT & $\begin{array}{l}\text { GGAAAAGACTTCCTACATTGTGTCCTGGA- } \\
\text { AAACAAAGAGAAAGAAAGACAGACTTTA- } \\
\text { CAAAAGG }\end{array}$ & 0.05 & 0.04 & 0.56 \\
\hline
\end{tabular}

${ }^{a}$ Pilot probe. ${ }^{\mathrm{b}}$ Control probes that hybridize on autosomal chromosomes. ${ }^{\mathrm{c}}$ The $5^{\prime}$ half-probes are preceded by the universal tag sequence GGGTTCCCTAAGGGTTGGA; the 3' half-probes are followed by the universal tag sequence TCTAGATTGGATCTTGCTGGCAC and are phosphorylated at the $5^{\prime}$ end. ${ }^{\mathrm{d}}$ Median of 4 male controls normalized using female controls.

patient suffers from DMD showing the typical characteristics with decreasing muscle strength over time. Presently, he has significantly reduced movement abilities and is wheelchair bound. Laboratory investigation reveals elevated levels for creatine kinase 5,630 U/l (normal value $<247$ ) and aspartate aminotransferase (75 U/1, normal range $10-50)$. Triglyceride levels are continuously increased $(450 \mathrm{mg} / \mathrm{dl}$, normal value $<200)$. A karyotype analysis revealed a normal male $46, \mathrm{XY}$ status without noticeable deletions within the $\mathrm{X}$ chromosome. Of note is a short stature $(128.5 \mathrm{~cm},-4.0 \mathrm{SDS})$, aggravated by the lack of puberty, and obesity (body mass index 27.1 + 2.4 SDS). The patient showed a speech and psychomotor delay starting in infancy. He has persistent verbal deficits as well as severe MR. Furthermore, he suffers from generalized seizures and is currently treated with lamotrigine.

Patient 4 is currently 6.7 years old and shows AI combined with an attention deficit disorder and verbal deficits. He has a history of speech and psychomotor delay starting in infancy. Laboratory results for creatine kinase, aspartate aminotransferase and triglyceride levels are within the normal range for age and sex.

Patient 5 is a 1.7-year-old infant with apparent isolated AI. A developmental deficit or metabolic crisis was not recorded so far.
Additional laboratory investigations revealed elevated levels of urinary glycerol $(1,680 \mathrm{mmol} / \mathrm{mol}$ creatine, control range undetectable).

\section{Multiplex Ligation-Dependent Probe Amplification}

Synthetic probes for MLPA were designed as previously described $[6,17]$. Some probes were already available at our laboratory from previous studies $[6,18]$, others were newly designed. The complete DAX1-del probe set (table 1) was tested in normal controls. The EK1 reagent kit (MRC Holland, Amsterdam, The Netherlands) was used for the MLPA reaction, according to the manufacturer's recommendation, starting from $100 \mathrm{ng}$ of genomic DNA for each sample. The PCR products were separated by capillary electrophoresis on an ABI 3100 genetic analyzer (Applied Biosystems). Trace data were analyzed using the GeneMapper version 3.7 software, and the integrated peak heights and areas were exported to an Excel spreadsheet (Microsoft) for further calculations. For each sample, the peak height/area was first normalized to the average peak height/area of the three control probes, followed by normalization to the average peak height/area of the control samples included in the run. The anal- 
Fig. 2. DAX1-del probe set and NROB1 deletion representation. Representation from the UCSC genome browser (March 2006, NCBI36, hg18) of the NROB1 locus on $\mathrm{Xp} 21$. Probes included in the DAX1-del set are represented as vertical red lines. Green horizontal lines represent the minimal deleted regions. $\mathrm{Pt}=$ Patient.

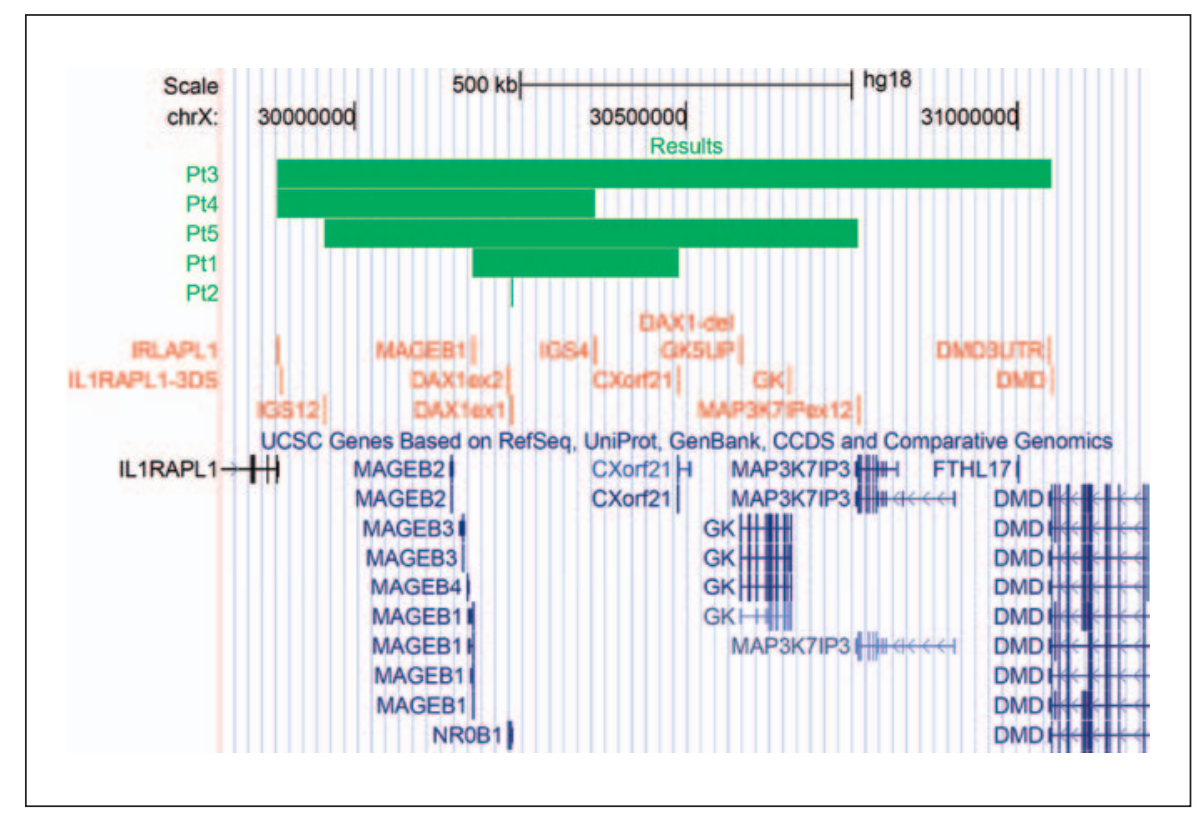

ysis was considered acceptable if the ratio for the internal control was between 0.8 and 1.2. Threshold values for deletions and duplications were set at 0.75 and 1.25 , respectively. When analyzing male patients for deletion, a visual inspection is sufficient as the probes within a deletion on the $\mathrm{X}$ chromosome result as missing (fig. 1).

\section{Copy Number Determination with Cyto2.7M}

For microarray analysis, the Cyto2.7M array platform was used (Affymetrix, Santa Clara, Calif., USA). Experimental procedures were performed according to the protocols provided by the manufacturer (Affymetrix; http://www.affymetrix.com). Microarrays were washed and stained with the Fluidics Station 450 (Affymetrix) and scanned with the GeneChip Scanner 3000 (Affymetrix). Copy number analyses of the Cyto2.7M array was performed using the Chromosome Analysis Suite Software (version 1.0.1, annotation file 30.0; Affymetrix). Mapping was done according to NCBI genome build 36 .

\section{Results}

\section{Multiplex Ligation-Dependent Probe Amplification}

The DAX1-del probe set (table 1) was tested in 6 female and 4 male controls. SD was calculated for the 6 female controls and all probes had a $\mathrm{SD}<10 \%$, thus proving to be reliable and sufficiently consistent (table 1). For the probes on the $\mathrm{X}$ chromosome, the median ratio value in the male controls, when calculated against the average of the female control values, ranged from 0.53 to 0.60 , being consistent with a hemizygosity value (table 1).
A summary of the results is presented in figure 2. Patient 1 showed missing peaks corresponding to the region covered by probe MAGEB1 thorough probe CXorf21. Therefore, he carries a deletion extending from MAGEB1, including NROB1, to the CXorf21 gene. The deletion was maternally inherited. Patient 2 carries a deletion of only the first exon of NROB1 which in fact could not be amplified by PCR; exon 2 is still present. Also in this case, the mutation was maternally inherited. All probes on Xp21 were absent in patient 3 , so the extension of the deletion was not established but extends to at least the last exon of IL1RAPL1, telomerically, and to the last exon of the $D M D$ gene, centromerically. A maternal sample was not available for this patient. A deletion affecting the entire NROB1 extending to the IL1RAPL1 gene was detected in patient 4 and his mother; both probes on the IL1RAPL1 were missing, thus the extension of the telomeric breakpoint could not be determined. A deletion from IGS12 to MAP3K7IP3ex12 probes, including the NROB1 and GK genes, was detected in patient 5. Again, the deletion was inherited from the mother.

\section{Microarray Analysis}

To unravel the extension of the deletion and the corresponding breakpoints in index patients 3 and 4, we performed a microarray analysis with the Cyto2.7M platform. In index patient 3, we detected an approximately 2,204-kb deletion on chromosome Xp21.3p21.3 with the 


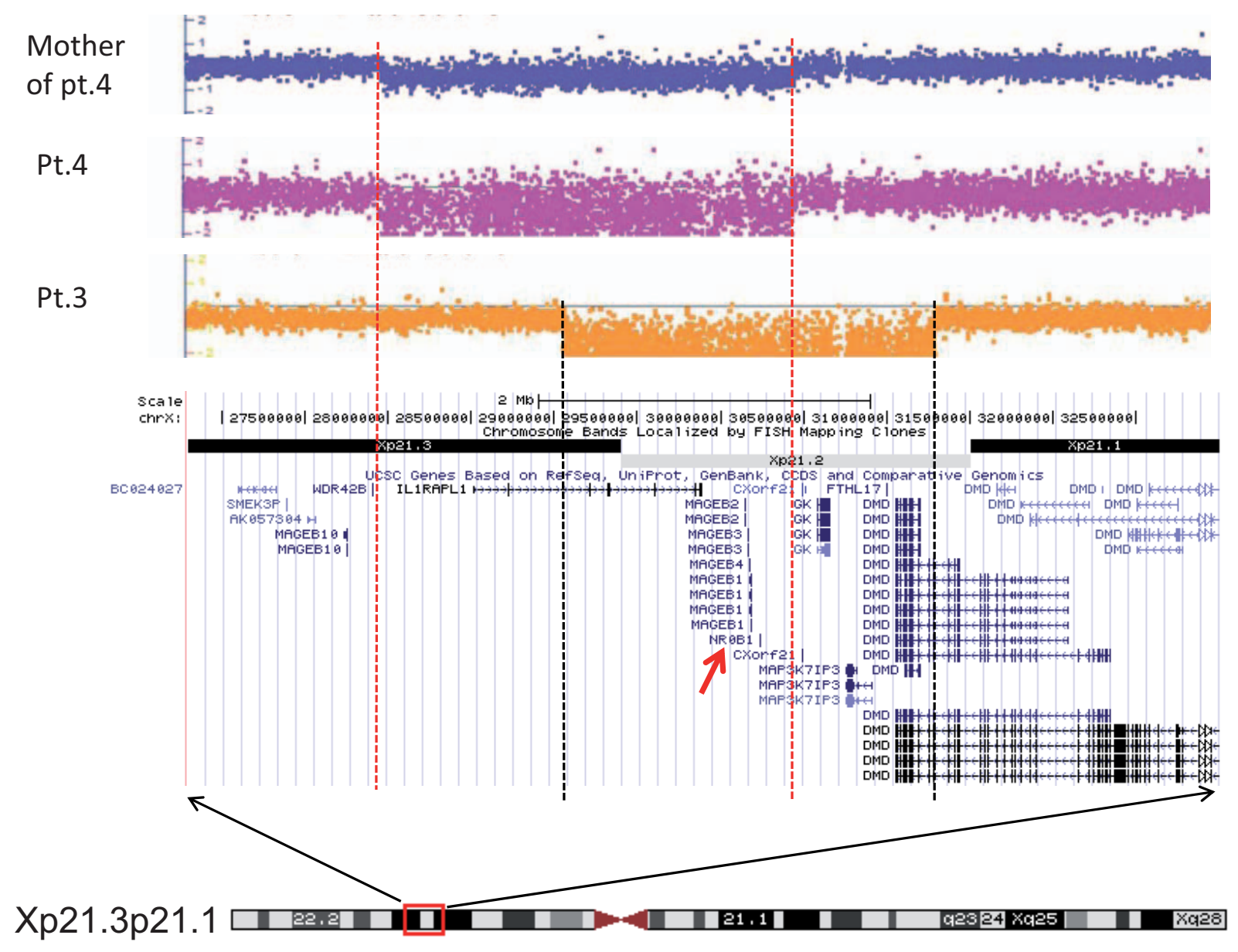

Fig. 3. Results of microarray analysis with the Cyto2.7M platform. Microarray results for the index patient (Pt.) 4 , the mother of patient 4 , and patient 3 . The figure includes a map of the deleted chromosomal region with a close-up view of the genes lying within the deleted region (parts of the figure were composed with the UCSC genome browser). The position of NROB1 (DAX1) is indicated by the red arrow.

most telomeric deleted probe starting at chrX:29,065,611 $\mathrm{bp}$ and the most centromeric deleted probe ending at chrX:31,270,355 bp (arrXp21.3.p21.3)(29,061,807x1,29, $065,611 \times 0-31,270,355 \times 0,31,271,211 \times 1)$. For index patient 4 , we detected an approximately 2,348-kb-sized deletion on chromosome Xp21.3p21.2, with the most telomeric deleted probe starting at chrX:27,988,531 bp and the most centromeric deleted probe ending at chrX:30,427,408 bp (arrXp21.3p21.2)(27,985,052x1,27,988,531x0-30,427, $408 \times 0,30,428,437 \mathrm{x} 1)$. His mother is heterozygous for this deletion (fig. 3).

\section{Discussion}

The manifestation of AI in the context of AHC may be the first symptom of a CGS. While AI is usually a symptom of early infancy, the additional features seen in the CGS like DMD, GKD and MR are most often detected with major delay. In order to accelerate the diagnostic workup and to allow genetic counseling of the affected families, the DAX1-del probe set was developed with the aim to characterize the extension of deletions within the NROB1 locus as the neighboring genes ILRAPL1, GK and 
$D M D$ are responsible for the additional symptoms in case of AHC due to a CGS.

Probes were tactically designed within the two exons of the NROB1 gene in order to detect single-exon as well as entire gene deletions; probe GK5UP is located $65 \mathrm{bp}$ upstream the GK gene (according to USCS genome browser, March 2006 NCBI36/hg18) in order to identify deletions extending very near but not including the $G K$ gene; probe GK is located instead within the last GK intron; probes DMD and DMD3UTR were placed within the last coding exon and at the very end of the $3^{\prime} \mathrm{UTR}$ of the DMD genes, respectively, in order to detect the most possible terminal deletions. For IL1RAPL1, probes were placed within the last exon (IL1RAPL1) and $5.5 \mathrm{~kb}$ downstream the gene (IL1RAPL1-3DS), again in order to identify deletions that extend to the very end of the gene. Probes within intergenic regions (IGS4 and IGS12) and other genes (MAGEB1, CXorf21 and MAP3K7IP3ex12) were included to confirm the deletion results for the probes within the genes of interest.

With our probe set, we analyzed 5 patients with AHC due to NROB1 deletions, previously detected by PCR, and evaluated the correlation of the phenotype with the extension of deletion to the neighboring genes. In patient 1 , in addition to NROB1, the deletion also affects MAGEB1 and CXorf 21 but does not reach either IL1RAPL1 or GK, thus confirming the isolated AHC phenotype. In patient 2 , a deletion affecting exon 1 but not exon 2 was suspected by PCR analysis and confirmed by MLPA. This is the first report of a deletion affecting only the first exon of NROB1. A complex rearrangement consisting of a $2.2-\mathrm{kb}$ deletion affecting exon 2 together with a 27-bp insertion has also been described [19], indicating the importance of having probes within both NROB1 exons. Moreover, MLPA analysis allowed the exclusion of a deletion extending to the upstream region of the GK gene. Thus, a possible metabolic crisis is excluded and the isolated AHC phenotype confirmed. In patient 3 , all probes were deleted, confirming the clinical and laboratory phenotype of AHC and HH due to NROB1 deletion, GKD and DMD. With the Cyto2.7M microarray platform, we confirmed the results from the MLPA analysis. Moreover, we were able to map the deleted region and the corresponding breakpoints. The deleted region contains the genes ILRAPL1, MAGEB2, CXorf21, GK, MAP3K7IP3, FTHL17 and $D M D$. The seizures may be a consequence of GKD. Furthermore, the deletion of IL1RAPL1 may aggravate the mental phenotype. Short stature has been described in a family with a deletion of IL1RAPL1 [14].

MLPA Analysis of the NROB1 Locus in AHC Patients
The NROB1 deletion in patient 4 extends telomerically to IL1RAPL1, explaining his MR phenotype. The GK gene on the other hand is not affected, and the development of a metabolic crisis can be excluded. Once more, MLPA results were reproducible with the microarray analysis. Mapping of the deletion confirmed that $G K$ is not lying in the deleted region. The deletion in patient 5 also affects the GK gene, but not IL1RAPL1. In fact, a MR phenotype has not yet been shown by the patient; however, he is at risk of a metabolic crisis and a consequent mental phenotype due to GKD.

We conclude that with our MLPA analysis we confirmed a phenotype/genotype correlation in patients with AHC due to CGS, where all patients with MR carry a deletion affecting also the ILIRAPL1 gene. Furthermore, patients at risk of metabolic crisis could be identified. It is of note that while GKD and DMD can also be ruled out by measuring glycerol, triglycerides and creatine kinase, respectively, no markers for MR are available, making the detection of IL1RAPL1 deletions in very young patients of significant help for the prognosis of the patient. However, it is important to remember that a severe adrenal crisis due to AHC can lead to brain damage and consequent MR, as well as that GKD can lead to psychomotor impairment as a consequence of hypoglycemic episodes [8]. These two latter causes of MR can be prevented with optimal medical management. The identification of the genetic rearrangement in AHC patients offers not only a more accurate genetic counseling to the family but also a better management of the patients. It allows the identification of a still asymptomatic affected male within the family, thus preventing life-threatening adrenal crises. Furthermore, the identification and characterization of a deletion allows the prevention and early management of different symptoms due to the other genes involved in the mutation.

Compared to a PCR approach, MLPA analysis is less laborious, as several target genes can be screened in one reaction, and it offers the advantage of detecting heterozygous deletions in female subjects, who, depending on the extension of the deletion, have a high risk of having children with MR, AHC, GKD and DMD. The risk is actually $50 \%$ for having an affected son and $50 \%$ for having a carrier daughter. Although the majority of female carriers of X-linked diseases are asymptomatic, some can present symptoms due to skewed X inactivation. In fact, delayed puberty showed by some female carriers of NROB1 mutations is postulated to arise due to a non-random $\mathrm{X}$ inactivation [20]. Furthermore, a female with salt-losing AHC, GKD and mild dystrophi-

Horm Res Paediatr 2012;77:100-107 
nopathy due to skewed $\mathrm{X}$ inactivation of the normal $\mathrm{X}$ chromosome, instead of the $\mathrm{X}$ chromosome carrying the contiguous gene deletion including NROB1, GK and part of the DMD gene, was recently described [21]. $\mathrm{X}$ inactivation was also shown to be complete on lymphocytes and skewed 80:20\% in muscle. DMD female carriers manifesting milder symptoms have also been described [22]. Thus, female carriers of NROB1 as well as of $G K$ or DMD mutations are at risk of developing symptoms, due to non-random $\mathrm{X}$ inactivation. Furthermore, in case of a contiguous gene deletion, the manifestation of the symptoms depends on the pattern of $\mathrm{X}$ inactivation in different tissues. All this makes the detection of female carriers of deletions even more important. Array-based platforms to evaluate copy number changes can also be used to identify and narrow down deletion extensions; however, the resolution depends on the platform of choice and the location of the probes, as relatively small deletions can escape detection (NROB1 is only $5 \mathrm{~kb}$ ). A combination of methods may be especially helpful in mapping larger deletions, as shown here for index patients 3 and 4 . In our assay, the placement of one probe on each NROB1 exon guarantees the identification of deletions affecting only one exon, and the location of probes at the very end of the ILIRAPL1 and DMD genes allow the identification of deletions extending to the very end of these genes. A disadvantage of MLPA, common to the other quantitative methods (i.e. quantitative PCR arrays, platforms), is that it cannot identify chro- mosome rearrangements, such as inversions and translocations that do not affect the copy number but can still affect proper gene expression [23].

To conclude, MLPA analysis is a valuable tool to detect NROB1 and contiguous gene deletions in patients with AHC. The investigation has shown a good genotype-phenotype correlation. It is especially helpful for the detection of IL1RAPL1 deletions causing MR. Furthermore, MLPA has the advantage of identifying female carriers.

\section{Acknowledgments}

The study was supported by EuroDSD (in the European Community's Seventh Framework Program FP7/2007-2013) under grant agreement No. 201444 (WP05 to F.G.R. and WP04 to S.B. and P.-M.H.). F.G.R. and P.-M.H. are members of the German National BMBF (Ministry of Education and Science)-funded DSD research network (Netzwerk Intersexualität). Microarray analyses were performed within the framework of a pilot study supported by Affymetrix.

\section{Disclosure Statement}

The POP study for Cyto2.7 was conducted under a contract between Affymetrix and the University Hospital Schleswig Holstein, Campus Kiel, Kiel, Germany, in which Affymetrix provided all reagents.

\section{References}

1 Ferraz-de-Souza B, Achermann JC: Disorders of adrenal development. Endocr Dev 2008;13:19-32.

-2 Zanaria E, Muscatelli F, Bardoni B, Strom TM, Guioli S, Guo W, Lalli E, Moser C, Walker AP, McCabe ER, et al: An unusual member of the nuclear hormone receptor superfamily responsible for X-linked adrenal hypoplasia congenita. Nature 1994;372:635641.

3 Muscatelli F, Strom TM, Walker AP, Zanaria E, Recan D, Meindl A, Bardoni B, Guioli S, Zehetner G, Rabl W, Schwarz HP, Kaplan J, Camerino G, Meitinger T, Monaco AP: Mutations in the $D A X-1$ gene give rise to both $\mathrm{X}$-linked adrenal hypoplasia congenita and hypogonadotropic hypogonadism. Nature 1994;372:672-676.
4 Guo W, Burris TP, McCabe ER: Expression of $D A X-1$, the gene responsible for X-linked adrenal hypoplasia congenita and hypogonadotropic hypogonadism, in the hypothalamic-pituitary-adrenal/gonadal axis. Biochem Mol Med 1995;56:8-13.

5 Bardoni B, Zanaria E, Guioli S, Floridia G, Worley KC, Tonini G, Ferrante E, Chiumello G, McCabe ER, Fraccaro M, et al: A dosage sensitive locus at chromosome Xp21 is involved in male to female sex reversal. Nat Genet 1994;7:497-501.

-6 Barbaro M, Oscarson M, Schoumans J, Staaf J, Ivarsson SA, Wedell A: Isolated 46, XY gonadal dysgenesis in two sisters caused by a Xp21.2 interstitial duplication containing the DAX1 gene. J Clin Endocrinol Metab 2007;92:3305-3313.
7 Lin L, Gu WX, Ozisik G, To WS, Owen CJ, Jameson JL, Achermann JC: Analysis of DAX1 (NROB1) and steroidogenic factor-1 (NR5A1) in children and adults with primary adrenal failure: ten years' experience. J Clin Endocrinol Metab 2006;91:30483054.

8 Sjarif DR, Ploos van Amstel JK, Duran M, Beemer FA, Poll-The BT: Isolated and contiguous glycerol kinase gene disorders: a review. J Inherit Metab Dis 2000;23:529-547.

-9 Dipple KM, Zhang YH, Huang BL, McCabe LL, Dallongeville J, Inokuchi T, Kimura M, Marx HJ, Roederer GO, Shih V, Yamaguchi S, Yoshida I, McCabe ER: Glycerol kinase deficiency: evidence for complexity in a single gene disorder. Hum Genet 2001;109:5562. 
10 Desguerre I, Mayer M, Christov C, Leturcq F, Chelly J, Gherardi RK: Phenotypic heterogeneity of Duchenne myopathy and prognosis criteria. Arch Pediatr 2009;16: 681-683.

11 Carrie A, Jun L, Bienvenu T, Vinet MC, McDonell N, Couvert P, Zemni R, Cardona A Van Buggenhout G, Frints S, Hamel B, Moraine C, Ropers HH, Strom T, Howell GR, Whittaker A, Ross MT, Kahn A, Fryns JP, Beldjord C, Marynen P, Chelly J: A new member of the IL-1 receptor family highly expressed in hippocampus and involved in $\mathrm{X}$-linked mental retardation. Nat Genet 1999;23:25-31.

-12 Jin H, Gardner RJ, Viswesvaraiah R, Muntoni F, Roberts RG: Two novel members of the interleukin-1 receptor gene family, one deleted in Xp22.1-Xp21.3 mental retardation. Eur J Human Genet 2000;8:87-94.

13 Zhang YH, Huang BL, Niakan KK, McCabe LL, McCabe ER, Dipple KM: IL1RAPL1 is associated with mental retardation in patients with complex glycerol kinase deficiency who have deletions extending telomeric of DAX1. Hum Mutat 2004;24:273.

14 Nawara M, Klapecki J, Borg K, Jurek M, Moreno S, Tryfon J, Bal J, Chelly J, Mazurczak T: Novel mutation of IL1RAPL1 gene in a nonspecific X-linked mental retardation (MRX) family. Am J Med Genet A 2008; 146A:3167-3172.
15 Tabolacci E, Pomponi MG, Pietrobono R, Terracciano A, Chiurazzi P, Neri G: A truncating mutation in the ILIRAPL1 gene is responsible for X-linked mental retardation in the MRX21 family. Am J Med Genet A 2006; 140:482-487.

16 Kulle AE, Riepe FG, Melchior D, Hiort O, Holterhus PM: A novel ultrapressure liquid chromatography tandem mass spectrometry method for the simultaneous determination of androstenedione, testosterone, and dihydrotestosterone in pediatric blood samples: age- and sex-specific reference data. J Clin Endocrinol Metab 2010;95:2399-2409.

17 Stern RF, Roberts RG, Mann K, Yau SC, Berg J, Ogilvie CM: Multiplex ligation-dependent probe amplification using a completely synthetic probe set. Biotechniques 2004;37:399405.

18 Barbaro M, Cicognani A, Balsamo A, Lofgren A, Baldazzi L, Wedell A, Oscarson M: Gene dosage imbalances in patients with $46, \mathrm{XY}$ gonadal DSD detected by an inhouse-designed synthetic probe set for multiplex ligation-dependent probe amplification analysis. Clin Genet 2008;73:453-464.
9 Salvi R, Gomez F, Fiaux M, Schorderet D, Jameson JL, Achermann JC, Gaillard RC, Pralong FP: Progressive onset of adrenal insufficiency and hypogonadism of pituitary origin caused by a complex genetic rearrangement within $D A X-1$. J Clin Endocrinol Metab 2002;87:4094-4100.

20 Seminara SB, Achermann JC, Genel M, Jameson JL, Crowley WF Jr: X-linked adrenal hypoplasia congenita: a mutation in DAX1 expands the phenotypic spectrum in males and females. J Clin Endocrinol Metab 1999;84:4501-4509.

-21 Shaikh MG, Boyes L, Kingston H, Collins R, Besley GT, Padmakumar B, Ismayl O, Hughes I, Hall CM, Hellerud C, Achermann JC, Clayton PE: Skewed X inactivation is associated with phenotype in a female with adrenal hypoplasia congenita. J Med Genet 2008; $45: e 1$.

22 Yoshioka M, Yorifuji T, Mituyoshi I: Skewed $\mathrm{X}$ inactivation in manifesting carriers of Duchenne muscular dystrophy. Clin Genet 1998;53:102-107.

23 Skinningsrud B, Husebye ES, Gilfillan GD, Frengen E, Erichsen A, Gervin K, Ormerod E, Egeland T, Undlien DE: X-linked congenital adrenal hypoplasia with hypogonadotropic hypogonadism caused by an inversion disrupting a conserved noncoding element upstream of the NROB1 (DAX1) gene. J Clin Endocrinol Metab 2009;94:4086-4093. 